RESEARCH PAPER

\title{
Effect of the New York State cigarette fire safety standard on ignition propensity, smoke constituents, and the consumer market
}

\author{
G N Connolly, H R Alpert, V Rees, C Carpenter, G F Wayne, D Vallone, H Koh
}

Tobacco Control 2005;14:321-327. doi: 10.1136/tc.2005.011759

See end of article for authors' affiliations

Correspondence to: Gregory N Connolly, DMD, MPH, Harvard School of Public Health, Division of Public Health Practice, Landmark Building, 677 Huntington Avenue, Boston, MA 02115, USA; gconnoll@ hsph.harvard.edu

Received 5 March 2005 Accepted 11 June 2005

\begin{abstract}
Objectives: This study examines empirical evidence from the New York experience testing tobacco industry arguments made in opposition to fire safety standards for cigarettes.

Design: Percentages of cigarettes exhibiting full length burns (FLBs), cigarette sales before and following the implementation of the New York standards, a sample of retail cigarette prices, brand availability, and selected smoke constituent yields were compared between cigarettes sold in New York and two other states. Cigarette paper analysis was conducted on cigarettes sold in New York.

Results: New York cigarette brands averaged 10.0\% FLBs as compared to $99.8 \%$ for California and Massachusetts brands. Reduced ignition propensity (RIP) appears to have been achieved by cigarette paper banding. Cigarette sales, prices, and brand availability do not appear to have been affected by the New York standards. Yields of the majority of smoke constituents tested did not differ substantially between RIP cigarettes sold in New York as compared to the same brands sold in Massachusetts. Average yields of tar, carbon monoxide, and two compounds were slightly higher, the yields of seven compounds were higher for one brand only, and nicotine was lower, among New York brands tested.

Conclusions: RIP cigarette brands have been designed to meet the New York fire safety standards. Their introduction has not affected cigarette sales or prices in New York. There is no evidence that the small increases in smoke constituent yields affect the already highly toxic nature of cigarette smoke. Data on smoking caused fires, deaths, and injuries dating from after the change in law are not yet available. Such data will be able to address the question of whether the demonstrated reduced ignition standards are associated with reduced fires and injuries. Based on the New York experience, prior industry objections to producing RIP cigarettes are unfounded. Other states and nations should adopt similar standards.
\end{abstract}

C igarettes and other lighted tobacco products are the leading cause of fire deaths and the third leading cause of fire related injuries in the USA. In 2001, 31200 civilian lives lost as well as firefighter fatalities, 1770 persons injured, and $\$ 386$ million in direct property damage. ${ }^{1}$ Other costs include health care costs, lost productivity, and use of fire and emergency services. Furthermore, two out of five victims of cigarette induced fires are not the smokers themselves but persons who live in the same building. These victims often include young children or older persons who are less able to respond to and escape from the fire. ${ }^{2}$ In a 1993 study, $75 \%$ of US households that experienced a cigarette fire had an annual household income level of less than $\$ 20000$ per year. $^{3}$

Legislation requiring less fire prone cigarettes has been introduced since 1974 in the USA at the federal level as well as in over a dozen states. However, none were successful until August 2000 when the state of New York passed legislation that called for the Office of Fire Prevention and Control to promulgate an ignition propensity standard by 1 January 2003. This legislation required all cigarettes sold in the state of New York to have reduced ignition propensity (RIP) by July 2003. Implementation of the law was delayed until 28 June 2004, when the New York Fire Safety Standards for Cigarettes (FSSC), Part 429 of Title 18 of the Official Compilation of Codes, Rules, and Regulations of the State of New York became effective.

For decades, the tobacco industry has opposed passage of state and federal legislation requiring cigarette fire safety standards. The industry has argued that RIP cigarettes would be technically unfeasible to develop, would increase product toxicity, and would prove unacceptable to consumers. ${ }^{4-11}$ The tobacco industry has also denied the efficacy of the proposed standards to reduce fires, and the overall morbidity, mortality, and costs associated with cigarette induced fires. ${ }^{4}$

This study examines New York's initial experience implementing fire safety standards for cigarettes and provides a preliminary assessment of the ability of manufacturers to produce cigarettes with reduced ignition propensity, while maintaining price and consumer acceptability, and with no substantial increase in smoke constituent yields. The study compares laboratory testing of RIP of cigarette brands sold in New York with those sold in Massachusetts and California, two states in which similar legislation has been proposed; and examines one of the design features, "banding", used by manufacturers to comply with the requirement in New York. It further examines measures of tax revenue, pricing, and brand availability to assess the effects of fire safety standards on the consumer market. Finally, it compares laboratory yields of a selection of known smoke constituents in cigarette brands sold in New York and Massachusetts to identify any substantial increases in the smoke constituent yields.

Abbreviations: ASTM, American Society of Testing and Materials; FLB, full length burn; FSSC, Fire Safety Standards for Cigarettes; FTC, Federal Trade Commission; PAH, polynuclear aromatic hydrocarbons; RIP, reduced ignition propensity; TPM, total particulate matter 


\section{METHODS}

\section{Ignition propensity}

In accordance with the American Society of Testing and Materials (ASTM) standard E2187-02b, the New York FSSC sets a minimum standard which requires a lit cigarette to be placed on multiple layers of standard filter paper in a draftfree environment to determine whether or not the tobacco column burns through its full length. ${ }^{12}{ }^{13}$ The ASTM E2187$02 \mathrm{~b}$ uses 3, 10, or 15 layers of filter paper. A brand is in compliance with the New York standard if no more than 25\% of the 40 cigarettes tested in a trial exhibit full length burns (FLBs) on 10 layers of filter paper.

For this study, we obtained measures of ignition propensity in accordance with the FSSC-reported as the percentage of cigarettes exhibiting full length burns-for a matched sample of 40 cigarettes per brand type for five popular brand typesMarlboro Red Filter Hard Pack; Marlboro Lights Filter Hard Pack Flip Top; Newport Menthol Kings Filter Soft Pack; Camel Filter Hard Pack; and Kool Filter Kings Soft Packeach purchased separately in New York, Massachusetts, and California. Kidde Fenwal Combustion Research Center, the firm that provided baseline testing for the New York Office of Fire Prevention and Control, was commissioned to test the brands. Kidde Fenwal obtained identical results as National Institute of Standards and Technology and National Research Council Canada using the same test method for a single nonbanded cigarette, demonstrating high inter-laboratory reliability. Differences in FLB rates between New York and the other states were tested with Poisson regression.

\section{Efficacy of cigarette banding}

Cigarette banding is one highly publicised method to achieve reduced ignition propensity that utilises a recently patented paper, in which ultra-thin concentric paper bands are applied to the traditional cigarette paper. ${ }^{14}$ These bands, referred to as "speed bumps", cause the cigarette to extinguish if not smoked by restricting oxygen to the burning ember. Internal industry testing has demonstrated that the width and location of these bands may be used to control ignition propensity, with wider bands and lower inter-band width associated with greatest reduction in ignition propensity. ${ }^{14}$

To assess the utlisation of "banded paper" as a method to reduce cigarette ignition propensity in brands sold in New York, a cigarette paper analysis was conducted on 10 cigarettes for each of the above five brand types sold in New York, in accordance with the draft procedure put forth by the New York State Office of Fire Prevention and Control. This analysis provides data regarding the number and location of the paper bands.

\section{Consumer acceptability}

The tobacco industry has argued that RIP cigarettes could result in a significant loss in consumer acceptability. ${ }^{6}$ To assess one aspect of consumer acceptability, cigarette sales were compared before and after the FSSC went into effect. Monthly cigarette sales in New York, Massachusetts, and California were derived from cigarette excise tax revenues. Data obtained from the respective tax revenue departments of each state were used to determine the number of cigarette packs taxed by dividing the taxes collected by the respective state excise tax rates. US Census Bureau statistics of persons aged 18 years and older were used to calculate monthly per capita cigarette sales. ${ }^{15-17}$

To assess changes in consumption, analyses examined absolute change in monthly per capita cigarette sales as well as a change in trend of monthly sales. Monthly per capita cigarette sales volumes from July 2004 through February 2005 were compared with sales volumes in the previous year using analysis of variance, with Massachusetts and California included as controls. Independent variables included month, state, and presence or absence of the reduced ignition propensity requirement. A change in trend of monthly cigarette sales in New York following the FSSC should be reflected by a change in trend of the ratio of monthly cigarette sales in New York to monthly cigarette sales in Massachusetts or California occurring at the date of effect of the FSSC. Therefore, a change in trend of these ratios over the period July 2003 to February 2005 was examined using linear regression analysis. Cigarette consumption is expressed as the ratio of total sales, rather than per capita sales, in examining for a change in trend. Independent variables were time (month), state, presence or absence of the FSSC, and interaction between time and the presence or absence of the FSSC.

\section{Price}

Tobacco manufacturers also suggested that the potential cost of compliance with the FSSC would be prohibitive. ${ }^{18} \mathrm{~A}$ comparison of retail cigarette prices in Albany, New York and Boston, Massachusetts was used as a preliminary assessment of the potential effects of the FSSC on relative manufacturing and production costs. Albany was selected for a comparison since it has no county specific cigarette excise tax and for its proximity to Massachusetts.

Data were obtained for retail cigarette prices with a convenience sample from three types of establishments: gas stations, convenience stores, and pharmacies in New York and Massachusetts. Five separate, popular establishments within each category of these categories were queried on 10 January 2005 with regard to the pre-sales tax prices of four popular brand types (Marlboro Red Filter Hard Pack; Newport Menthol Kings Filter Soft Pack; Camel Filter Hard Pack; Kool Filter Kings Soft Pack) representing each of the major cigarette manufacturers. The price was documented as well as the specific source (that is, price as posted, price provided by store clerk, or price provided by store clerk upon scanning a pack). Any promotions and special discounts for these brands were also documented at the time of sampling. Student's $t$ test was used to test for a difference between presales and excise tax prices in the two cities. Results were considered statistically significant at $\mathrm{p} \leqslant 0.05$.

\section{Brand availability}

To assess the effect of the FSSC on the availability of cigarette brands in New York, a list of the brand families and subbrands certified by the New York Office of Fire Prevention and Control on 1 December 2004 was compared with all brands and sub-brands identified in the Massachusetts Department of Public Health's Annual Report for Nicotine Yield, filed on 1 December 2004 by the four major tobacco companies. Massachusetts has a unique state law requiring tobacco manufacturers to identify and report on an annual basis the nicotine yield of any cigarette brand they intend to sell in that state. Brand families consist of all styles or subbrands of cigarettes sold under the same trade mark and differentiated from one another by modifiers such as menthol, lights, kings, and 100s. These comparisons were made for brands of the major cigarette manufacturers noted above, which together account for more than $90 \%$ of all cigarettes sold in the USA. ${ }^{19}$

\section{Smoke constituent yields}

Machine testing of smoke constituent yields cannot predict actual human exposure or disease risk. It provides a crude measure of how design changes affect the smoke constituents under standardised machine testing protocols. This study examines a small number of brands (four) from New York and Massachusetts to assess whether there was any 


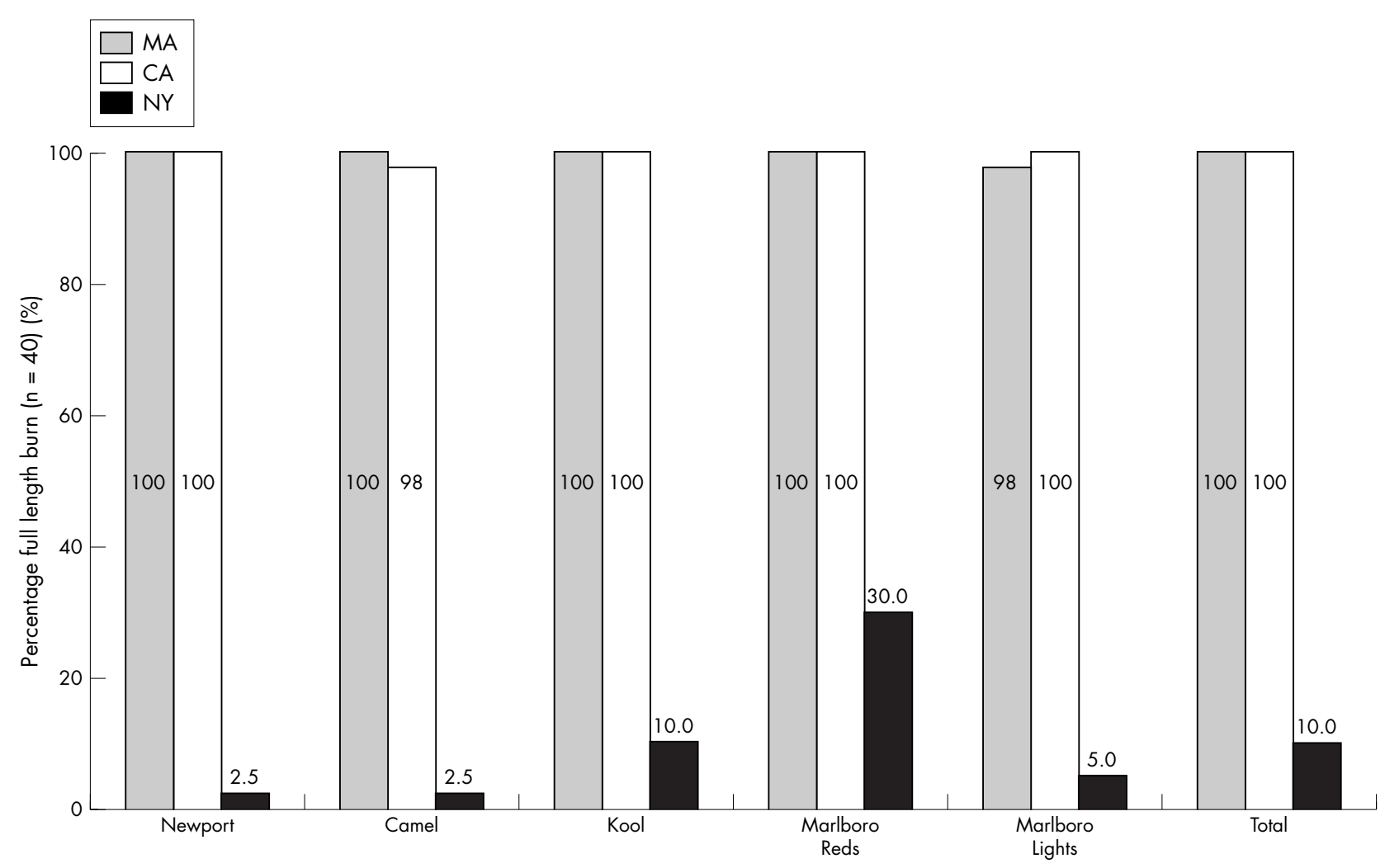

Figure 1 Ignition propensity of New York (NY), Massachusetts (MA), and California (CA) cigarettes.

evidence that the New York standard had resulted in a substantial increase of specific smoke constituent yields. A laboratory analysis was conducted of the smoke chemistry of 19 commonly known toxins of four matched cigarette brands (Marlboro Red Filter Hard Pack; Newport Menthol Kings Filter Soft Pack; Camel Filter Hard Pack; and Kool Filter Kings Soft Pack), purchased separately in New York and in Massachusetts on 10 and 11 December 2004. Smoke constituent yield analysis was conducted by Arista Laboratories, a certified cigarette testing laboratory.

Federal Trade Commission (FTC) machine measured yield ratings of selected smoke constituents of the vapour phase and particulate phase of mainstream smoke were determined for each selected brand style and for the Kentucky reference cigarette (2R4F). The analytes included carbonyls (formaldehyde, acetaldehyde, acetone, acrolein, propionaldehyde, crotonaldehyde, butryaldehyde, methylethylketone); polynuclear aromatic hydrocarbons (PAH) (naphthalene, flourene, phenanthrene, anthracene, fluoranthene, pyrene, benzo[a]anthracene, chrysene, benzo(a)pyrene, indeno[1,2,3-cd]pyrene); and "tar", nicotine, and carbon monoxide. The yield of total particulate matter (TPM), which is comprised of "tar", water, and nicotine, was also determined. Puff count per cigarette was measured as well.
A minimum of five separate replicate determinations was conducted for each analyte and sample brand style, and data are reported on a per cigarette basis. In order to test the hypothesis that yields differed between New York and Massachusetts cigarettes, the yield of each analyte was analysed using two way analysis of variance with independent variables state, brand style, and the interaction between the state and brand style. For models with both a significant main effect of state and interaction term, Student's $t$ tests were used to compare brand specific yields between the states. The average percentage differences in yield per brand was computed for models where a significant main effect of state was present, but not the interaction term; and brand specific percentage differences in yield were computed where both a significant main effect of state and interaction term were present. No adjustment was made for multiple comparisons, and results were considered significant at $\mathrm{p} \leqslant 0.05$.

\section{RESULTS}

Ignition propensity

All New York brands that were tested exhibited a reduced percentage of full length burns compared with their matched brands in Massachusetts and California as shown in fig 1 . A

Table 1 Monthly per capita cigarette pack sales in New York (NA), Massachusetts (MA), and California (CA)

\begin{tabular}{|c|c|c|c|c|c|c|c|c|c|c|c|c|c|c|c|c|}
\hline & \multicolumn{2}{|l|}{ July } & \multicolumn{2}{|c|}{ August } & \multicolumn{2}{|c|}{ September } & \multicolumn{2}{|c|}{ October } & \multicolumn{2}{|c|}{ November } & \multicolumn{2}{|c|}{ December } & \multicolumn{2}{|c|}{ January } & \multicolumn{2}{|c|}{ February } \\
\hline & 2003 & 2004 & 2003 & 2004 & 2003 & 2004 & 2003 & 2004 & 2003 & 2004 & 2003 & 2004 & 2004 & 2005 & 2004 & 2005 \\
\hline NY & 4.15 & 4.29 & 4.20 & 3.70 & 3.95 & 3.91 & 4.05 & 3.83 & 3.38 & 3.51 & 4.11 & 4.00 & 3.77 & 3.39 & 2.93 & 3.02 \\
\hline$M A$ & 5.62 & 5.66 & 4.87 & 4.84 & 4.91 & 4.88 & 4.66 & 4.59 & 4.60 & 4.71 & 4.88 & 5.06 & 4.76 & 4.11 & 4.11 & 4.19 \\
\hline $\mathrm{CA}$ & 4.01 & 6.10 & 4.95 & 2.74 & 2.97 & 3.21 & 3.08 & 4.10 & 2.69 & 2.89 & 5.26 & 5.55 & 3.15 & 3.17 & 3.01 & 2.48 \\
\hline
\end{tabular}


percentage of FLBs of $10 \%$ or lower was observed in four of the New York brands, and a percentage of 30\% FLBs was observed in one New York brand. In contrast, 98-100\% FLBs were observed in each of the brands tested in Massachusetts and California. The difference between percentage of FLBs exhibited by cigarettes in New York versus the other states was significant $(\mathrm{p}<0.001)$.

\section{Cigarette banding}

Cigarette paper analyses found "banded paper" utilised for each of the brands tested, suggesting that these cigarette manufacturers are using banding as a primary method to achieve RIP for these tested brands. The overall length of cigarettes analysed ranged from $77-82 \mathrm{~mm}$, and the length of the tobacco rod ranged from $56-62 \mathrm{~mm}$. The median number of bands was 2.0 for four of the brands and 2.5 for Camel. Mean band widths ranged from $4.7-5.3 \mathrm{~mm}$, and mean distance between bands ranged from 18.0-22.0 mm per New York brand. Band width and inter-band distances differed between the five brand types $(p<0.05)$, which indicates that manufacturers are using different banding techniques.

\section{Consumer acceptability}

Per capita cigarette sales from July 2003 through February 2004 and July 2004 through February 2005 are shown in table 1. No change was seen in New York in the six months following implementation of the FSSC compared with the corresponding time period in the previous year $(\mathrm{p}=0.646)$.

The ratios of total cigarette sales between New York and Massachusetts and between New York and California on a month to month basis are shown in fig 2 . Linear regression analyses revealed no changes in trend of cigarette sales ratios (New York: Massachusetts $\mathrm{p}=0.936$; New York: California $\mathrm{p}=0.812$ ) with the date of effect of the FSSC.

\section{Price}

Table 2 shows the average pre-sales and excise tax price per pack by brand type and state at gas stations, convenience stores, and pharmacies for four brand types in Albany and in Boston. Average price per pack did not differ by brand type or store type, but were slightly higher in Boston (\$3.27) than in Albany $(\$ 3.12)(\mathrm{p}=0.023)$.

\section{Brand availability}

The comparison of cigarette brands found that 41 of the 49 brand families (74\%) listed in the Massachusetts report
Table 2 Cigarette prices in Albany, NY and Boston, MA

Pre-sales and excise tax price per pack mean (SD) dollars (number of stores)

\begin{tabular}{|c|c|c|c|c|c|}
\hline Location & Camel & Kool & Marlboro & Newport & Total \\
\hline & & & & & \\
\hline & (1 & (1 & (1 & & 15 \\
\hline lbany, & 3.3110 & $3.00(0.44)$ & 3.1110 & ) 3.08 & $3.13(0.38)$ \\
\hline NY & (15) & (13) & (15) & (14) & (57) \\
\hline
\end{tabular}

Camel, Camel Filter Hard Pack; Kool, Kool Filter Kings Soft Pack; Marlboro, Marlboro Red Filter Hard Pack; Newport, Newport Menthol Kings Filter Soft Pack.

appeared on the New York State list of certified brands (table 3$)$. The total number of sub-brands reported to Massachusetts was 472, of which 342 (72.3\%) were certified by the New York Office of Fire Prevention and Control.

\section{Smoke constituent yields}

Table 4 provides results of the component analysis of the mainstream yields for 19 toxins in the smoke of the New York and Massachusetts brands in addition to their tar, nicotine, carbon monoxide, TPM yields, and machine smoked puff counts. Variability between brands as reflected by adjusted $R^{2}$ values accounted for $67-100 \%$ of the total variability in the analysis of variance models.

The average mean nicotine level was $1.8 \%$ lower, tar level was 3\% higher, and the mean average yield for carbon monoxide was $11.4 \%$ higher in New York brands compared with Massachusetts brands. Among the 19 major smoke constituents studied, the yields of the majority ${ }^{10}$ were not significantly different across brands, and the yields of seven were not significantly different in three out of the four brands. The yields of these seven compounds (all being polynuclear aromatic hydrocarbons) were significantly higher in New York among Newport brand cigarettes only. The magnitude of these differences was relatively small (11.3-19.9\%). Slightly elevated average yields of two compounds, fluorene and naphthalane $(6.1 \%$ and $13.9 \%$ increases, respectively), were also seen in New York.

\section{DISCUSSION}

These results demonstrate that cigarette manufacturers are able to produce RIP cigarettes in accordance with the New

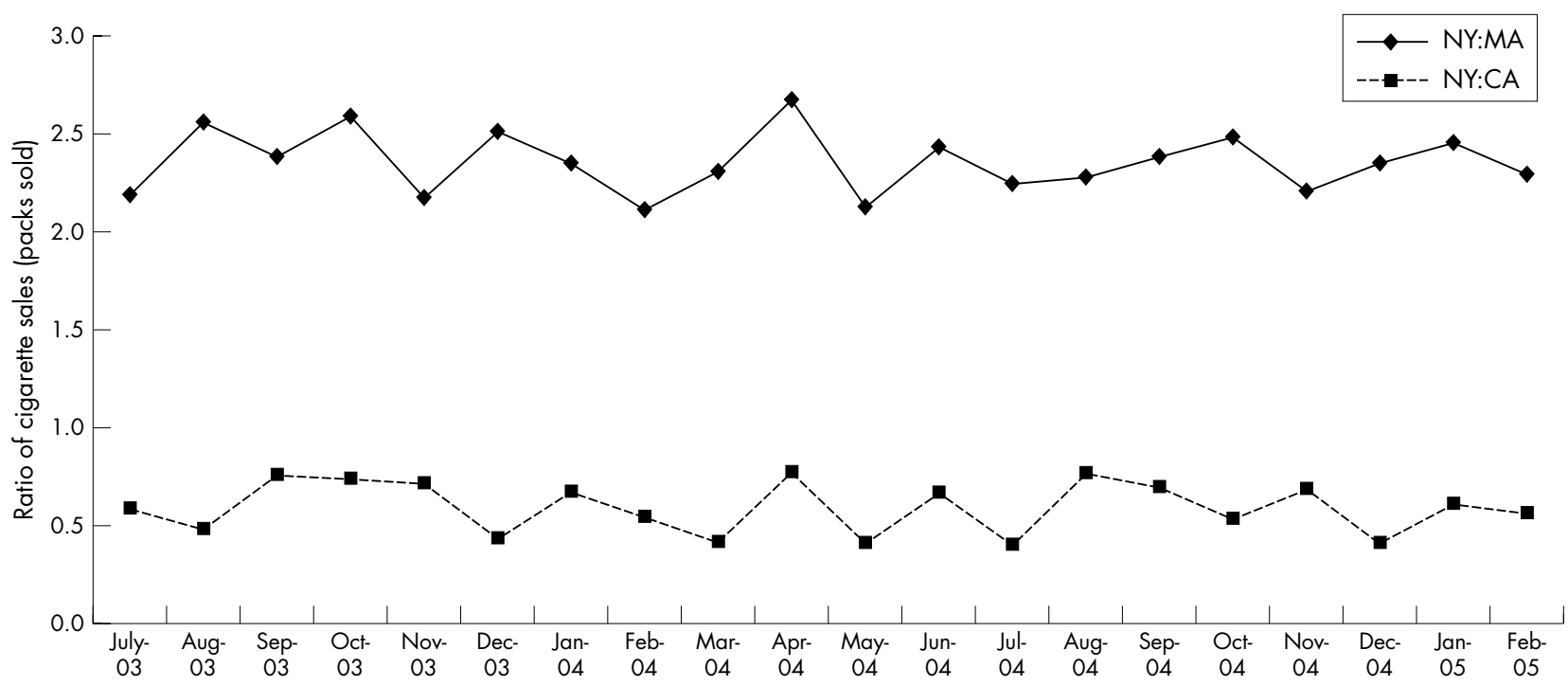

Figure 2 Cigarette sales over time. 
Table 3 Comparison of cigarette brand families and sub-brands sold in New York and Massachusetts

\begin{tabular}{|c|c|c|c|c|c|c|}
\hline \multirow[b]{2}{*}{ Manufacturer } & \multicolumn{2}{|c|}{$\begin{array}{l}\text { Number of brand } \\
\text { families }\end{array}$} & \multirow[b]{2}{*}{$\%$ difference ${ }^{*}$} & \multicolumn{2}{|c|}{$\begin{array}{l}\text { Number of } \\
\text { sub-brands }\end{array}$} & \multirow[b]{2}{*}{$\%$ difference* } \\
\hline & MA & NY & & $\overline{M A}$ & NY & \\
\hline Philip Morris & 16 & 13 & -18.8 & 122 & 114 & -6.6 \\
\hline Brown \& Williamson & 14 & 13 & -7.1 & 114 & 93 & -18.4 \\
\hline RJ Reynolds & 11 & 9 & -18.2 & 176 & 100 & -69.1 \\
\hline Lorillard & 8 & 6 & -24.1 & 60 & 35 & -41.7 \\
\hline Total & 49 & 41 & -16.3 & 472 & 342 & -27.5 \\
\hline
\end{tabular}

*\% difference is the difference in the number of brand families or sub-brands available in New York relative to the number that are available in Massachusetts.

York fire safety standards. Among the brands studied, banded paper appears to have been a primary method utilised for reducing ignition propensity. To the extent that these findings reflect the characteristics of cigarettes sold in New York today, these cigarettes are less prone to ignite fires than those sold in Massachusetts and California, and presumably other states.

The analysis demonstrates significant differences across brands in both band width and placement. Internal studies by Philip Morris observe that the technology used for placement of the paper bands is highly precise, ${ }^{14} 20$ which suggests that the brand differences are intentional. Thus, the role and effects of measured brand differences in band placement are an important area for future study, as are other design factors that may reduce ignition propensity such as the use of expanded tobacco, reduced paper permeability, reduced citrates in paper, and decreasing cigarette circumference. All major cigarette firms now have access to the banded paper first developed by Philip Morris. Thus, even countries in which Philip Morris's market share is relatively small can reasonably expect cigarette manufacturers to comply with an RIP law.

The data also suggest that the introduction of RIP brands has not affected consumer acceptability as evidenced by the lack of declining cigarette sales in New York compared to Massachusetts and California. These findings are consistent with statements put forth by Philip Morris, which reported a high degree of consumer satisfaction with their first banded paper cigarette product (Merit) claiming test results that were "overwhelmingly positive". ${ }^{21}$

Preliminary analysis provides no evidence of higher cigarette prices in Albany, New York as compared to Boston, Massachusetts. Indeed, the price markup appears to have been greater in Boston. The sample taken for pricing was limited in size, and conclusions drawn are provisional. Nonetheless, the data do not suggest any evidence of prohibitively increased manufacturing or production costs for RIP cigarettes.

Based on the cigarette brand comparison, the FSSC appears to have reduced the availability of only of a small number of older brands and sub-brands with very small market share that were listed in the Massachusetts Report but were not certified by New York, namely Raleigh (Brown and Williamson); Alpine, Bristol, and Players (Philip Morris); and Satin and Triumph (Lorillard). Data were not readily available regarding market share by sub-brand so that differences observed cannot be interpreted as a difference in the absolute numbers of cigarettes available in New York

Table 4 Yields of mainstream smoke constituents in New York and Massachusetts cigarettes

\begin{tabular}{|c|c|c|c|c|c|c|c|c|c|}
\hline \multirow{2}{*}{$\begin{array}{l}\text { Parameter or smoke } \\
\text { constituent (units/cig) }\end{array}$} & \multicolumn{2}{|l|}{ Camel } & \multicolumn{2}{|l|}{ Kool } & \multicolumn{2}{|c|}{ Marlboro Red } & \multicolumn{2}{|l|}{ Newport } & \multirow[b]{2}{*}{$\%$ increase } \\
\hline & MA & NY & MA & NY & MA & NY & MA & NY & \\
\hline Puffs per cigarette & 9.06 & 8.40 & 7.46 & 6.98 & 7.96 & 8.10 & 8.40 & 8.44 & \\
\hline Carbon monoxide (mg) & 13.49 & 15.60 & 13.79 & 15.77 & 12.60 & 13.48 & 17.17 & 18.68 & $11.4 \%(p<0.001)$ \\
\hline Nicotine (mg) & $1.21^{*}$ & 1.15 & $1.17^{* *}$ & 1.09 & 1.02 & 1.02 & 1.32 & 1.38 & \\
\hline Tar (mg) & 16.03 & 16.56 & 16.41 & 16.71 & 14.54 & 14.63 & 18.39 & 19.54 & $3.0 \%(p=0.014)$ \\
\hline Naphthalene (ng) & 868.60 & 968.69 & 796.47 & 898.88 & 780.61 & 851.21 & 950.48 & 1160.18 & $13.9 \%(p<0.001)$ \\
\hline Fluorene (ng) & 328.60 & 328.59 & 251.26 & 278.51 & 279.28 & 290.29 & 329.07 & 360.86 & $6.1 \%(p=0.007)$ \\
\hline Phenanthrene (ng) & 220.80 & 217.18 & 192.69 & 187.22 & 200.73 & 207.39 & 200.05 & $239.90^{* * *}(19.9 \%)$ & \\
\hline Anthracene (ng) & 79.98 & 80.16 & 67.52 & 68.01 & 74.04 & 76.10 & 73.20 & $86.88^{* * *}(18.7 \%)$ & \\
\hline Fluoranthene (ng) & 84.90 & 86.12 & 73.60 & 71.77 & 73.37 & 75.12 & 87.28 & $101.00 * * *(15.7 \%)$ & \\
\hline Pyrene (ng) & 65.62 & 65.42 & 55.02 & 51.36 & 56.68 & 58.05 & 63.45 & $72.87^{* * *}(14.8 \%)$ & \\
\hline Benzanthracene (ng) & 22.42 & 21.32 & 17.81 & 17.52 & 18.89 & 19.71 & 19.77 & $22.64^{* * *}(14.5 \%)$ & \\
\hline Chrysene (ng) & 24.86 & 23.33 & 19.74 & 19.03 & 20.80 & 21.71 & 23.63 & $27.42^{* \star *}(16.0 \%)$ & \\
\hline Benzo(e)pyrene (ng) & 7.05 & 6.89 & 5.55 & 5.49 & 5.58 & 5.73 & 6.62 & 7.36 & \\
\hline Benzo(a)pyrene (ng) & 9.20 & 8.79 & 7.26 & 7.03 & 7.76 & 7.92 & 7.87 & $8.76^{* * *}(11.3 \%)$ & \\
\hline Indeno[1,2,3-cd]pyrene (ng) & 6.14 & 5.68 & 4.59 & 4.83 & 5.09 & 4.96 & 5.55 & 6.06 & \\
\hline Formaldehyde $(\mu \mathrm{g})$ & 38.28 & 38.56 & 49.28 & 51.38 & 39.26 & 42.00 & 60.34 & 58.78 & \\
\hline Acetaldehyde $(\mu \mathrm{g})$ & 732.60 & 794.20 & 857.40 & 917.20 & 788.00 & 808.80 & 1044.20 & 1098.80 & \\
\hline Acetone $(\mu \mathrm{g})$ & 337.80 & 372.60 & 372.60 & 393.40 & 364.80 & 369.80 & 480.60 & 502.00 & \\
\hline Acrolein $(\mu \mathrm{g})$ & 78.02 & 79.40 & 92.00 & 98.10 & 86.08 & 85.16 & 107.70 & 111.60 & \\
\hline Propionaldehyde( $\mu \mathrm{g})$ & 63.48 & 69.50 & 72.76 & 78.30 & 68.60 & 70.44 & 89.70 & 94.62 & \\
\hline Crotonaldehyde $(\mu \mathrm{g})$ & 26.06 & 28.50 & 32.54 & 35.00 & 30.00 & 31.10 & 39.36 & 41.20 & \\
\hline Methylethylketone $(\mu \mathrm{g})$ & 98.84 & 110.00 & 105.48 & 113.20 & 104.56 & 106.32 & 142.60 & 148.40 & \\
\hline Butyraldehyde $(\mu \mathrm{g})$ & 37.78 & 40.12 & 41.08 & 42.94 & 40.48 & 41.06 & 51.90 & 54.20 & \\
\hline
\end{tabular}

${ }^{*} p=0.026 ;{ }^{* *} p=0.021 ;{ }^{* * *} p<0.001$

Average percentage increase is shown in right hand column, where main effect of state is significant in the absence of significant interaction between brand and state; $p$ values are for the $F$ test.

Brand specific percentage increase is shown in parentheses where the interaction between state and brand terms is significant; $p$ values for brand specific differences are for the Student's $t$ test. 
versus Massachusetts. Also, some brands or sub-brands that appear on the Massachusetts list might not actually be sold in that state.

These changes could reflect the manufacturers' decision that brands or sub-brands with extremely small market share were not worth modifying for the New York market. They may also reflect a greater difficulty in achieving compliance with the FSSC for some commercial brands. Even with minor differences in brand availability, the FSSC has not significantly reduced the absolute number of cigarettes sold in New York. Taken together, the cigarette consumption, brand availability, and pricing data strongly suggest that the New York FSSC has had little, if any, effect on the consumer market, indicating that New York RIP brands have not affected consumer acceptability.

The present study found some differences between cigarettes sold in New York and Massachusetts in the yields of specific smoke constituents in addition to tar, nicotine, and carbon monoxide (CO). Increases in the yields of tar, $\mathrm{CO}$, and polynuclear aromatic hydrocarbons were statistically significant, although the differences found were generally of small magnitude and were primarily driven by one (Newport) out of the four brands examined. There is no evidence that increases of this magnitude in one or more toxins would affect the already highly toxic nature of cigarette smoke. ${ }^{22}$ The purpose of this study was to test for major differences in the levels of smoke constituents, on the order of the $50-300 \%$ differences that have been previously observed across brands. ${ }^{23}$ The small sample (four sub-brands out of 767 certified sub-brands) and the high variability across these brands warrant viewing these results as preliminary and meriting further research.

Under the Fire-Safe Cigarette Act of 1990, the National Institute for Standards and Technology, using a larger sample of six commercial cigarette brand types, compared the Tobacco Institute Testing Laboratory values of the tar, nicotine, and CO yields of reduced ignition propensity with the values for the yields from the 14 best selling commercial cigarette brand types. ${ }^{24}$ No significant differences in levels of smoke constituents were found between the two sets of cigarettes. ${ }^{24}$ More research is needed regarding how smokers smoke conventional and commercial RIP brands versus nonRIP brands and what their actual bodily exposure is to toxins and disease.

This study must be viewed in light of its preliminary nature and the limited number of brands examined. Retailers were allowed a grace period of up to 180 days following 28 June 2004 to sell existing inventory. Any carryover of inventory during the initial period following implementation of the FSSC might affect conclusions regarding cigarette consumption. Further research is needed using a larger sample from the marketplace to confirm the findings regarding RIP, banding, and pricing. Nevertheless, the four represented brand families constitute $54 \%$ of all cigarettes sold nationally. ${ }^{19}$ Further, the present results are consistent with findings from internal industry research and the information that is found in industry documents regarding RIP, consumer acceptability, and smoke constituent yields.

The present findings show that the New York standard is effective in reducing ignition propensity. The tobacco industry has argued against RIP standards for cigarettes. The scientific evidence shows that ignition propensity test performance is a strong indicator of the risk of cigarette initiated fires. Incidence data not available at the time of this study are needed to demonstrate the long term effectiveness of the FSSC on reduction of fire deaths and injuries. The New York law includes an important provision to allow upgrading of the performance criteria in the future if necessary.

\section{What this paper adds}

Technologies and methods have been available for producing cigarettes with reduced ignition propensity and measuring their performance. The tobacco industry's arguments opposing legislative efforts to regulate ignition propensity, which are based on technical and economic feasibility, have remained untested in the absence of prior legislation. New York State's unique fir -safety standards for cigarettes provide the first opportunity to use empirical data to examine the validity of those claims. The present study examines the first six months of experience in New York and evaluates ignition propensity and cigarette banding; cigarette sales, prices, and brand availability; and smoke constituents in cigarettes sold in New York relative to cigarettes sold in other states. The present findings refute tobacco industry past arguments, and they support government policies requiring fire safety standards for cigarettes.

\section{Conclusion}

RIP cigarette brands have been designed to meet the New York fire safety standards. Their introduction has not affected cigarette sales or prices in New York. There is no evidence that the small increases in smoke constituent yields affect the already highly toxic nature of cigarette smoke. Data on smoking caused fires, deaths, and injuries dating from after the change in law are not yet available. Such data will be able to address the question of whether the demonstrated reduced ignition standards are associated with reduced fires and injuries. Based on the New York experience, prior industry objections to producing RIP cigarettes are unfounded. Other states and nations should adopt similar standards.

\section{ACKNOWLEDGEMENTS}

The authors thank Andrew McGuire, Richard O'Connor, Richard G Gann, Bruce Leistikow, Matthew Myers, Christine Judge, Ella Watson Stryker, and Gary Giovino for comments and suggestions, and Carole Smith for assistance in the preparation of this manuscript.

\section{Authors' affiliations}

G N Connolly, H R Alpert, V Rees, C Carpenter, G F Wayne, H Koh, Harvard School of Public Health, Boston, Massachusetts, USA D Vallone, American Legacy Foundation, Washington, DC, USA

This research was conducted at the Harvard School of Public Health and funded through the American Legacy Foundation grant 6212.

Competing interests: none declared

Ethics approval: Ethics committee approval was not required to be secured for the study reported.

\section{REFERENCES}

1 Hall J. The smoking-material fire problem. Fire Analysis and Research Division. Quincy, Massachusetts: National Fire Protection Association, 2004. 2 Leistikow BN, Martin DC, Milano CE. Fire injuries, disasters, and costs from cigarettes and cigarette lights: a global overview. Prev Med 2000;31:91-9.

3 Harwood B, Kissinger TL, Karter Jr M, et al. Cigarette Fire Incident Study: Technical Advisory Group, Fire Safe Cigarette Act of 1990; 1993. Report No. 4

4 Hearing on HR 3885, The Fire Safe Cigarette Act, Statement of Charles O Whitley on behalf of the Tobacco Institute. In: Subcommittee on Commerce, Consumer Protection and Competitiveness, Committee on Energy and Commerce. Washington DC, 1994.

5 Hearing on HR 3885, The Fire Safe Cigarette Act, Statement of R. J. Reynolds Tobacco Company. In: Subcommittee on Commerce, Consumer Protection and Competitiveness, Committee on Energy and Commerce, Washington DC, 1994.

6 Assessment of Public Comment - Fire Safety Standards for Cigarettes. 2003. http://www.dos.state.ny.us/fire/cigrulepc90303.htm.(Accessed Jan 3, 2005).

7 Philip Morris. 'Self-Extinguishing' Cigarettes. Bates Number: 2022963801/ 3802; 1982 May 20. 
8 Philip Morris. Status Of Research Regarding Low Ignition Propensity Cigarettes. A Discussion of Three Unresolved Issues That Make Cigarette Ignition Performance Standards Presently Infeasible. Bates No. 2021302717/2743, 1993.

9 RJ Reynolds. "Fire-Safe" Cigarettes. Legislative Status and Implications. Bates No. 508544401/4408; February 1, 1990.

10 RJ Reynolds. Cigarette Ignition Propensity Issues. Questions and Answers For Response Only. Bates Number: 508690094/0103; March, 1994.

11 Tobacco Institute. Issue Brief: "Self Extinguishing" Cigarette Legislation. Bates No. TIFL0071560-1561, 1987.

12 Addendum to: Derivation of Cigarette Fire Safety Performance Standard. New York Office of Fire Prevention and Control. August 15, 2003. http:// www.dos.state.ny.us/fire/pdfs/AddendumToDerivationReport0814.pdf (Accessed April 29, 2005).

13 ASTM E2187- 02b Standard Test Method for Measuring the Ignition Strength of Cigarettes, ASTM International 2002

14 Garg R. The development of banded cigarette paper to reduce fabric ignition propensity. Bates Number: 2062954842, Philip Morris USA, 2000

15 Monthly Tax Collection Reports. New York State Department of Taxation and Finance, 2005. http://www.tax.state.ny.us/collections/ monthly_tax_collections.htm (Accessed Jan 7, 2005).

16 Monthly Revenue Reports. Massachusetts Department of Revenue, 2005. http://www.dor.state.ma.us/stats/RevRpt/index.htm (Accessed Jan 7, 2005).
17 Statement of General Fund Cash Receipts and Disbursements. California State Controller, 2005. http://www.sco.ca.gov/ard/cash/index.shtml (Accessed Jan 7, 2005).

18 Revised Job Impact Statement. New York State, Department of State, 2003. http://www.dos.state.ny.us/fire/riiscig.htm (Accessed Jan 5, 2005).

19 Anon. Maxwell Tobacco Fact Book. Raleigh, North Carolina: SpecComm International, Inc, 2004.

20 Patskan G, Hsu F, Meisgen T, et al. Toxicological characterization of a novel cigarette paper. Bates Number: 2072790074, Philip Morris, 2000.

21 Philip Morris. Merit Paperselect (New) Letter. Bates No. 202823 5634/5637; 2000.

22 National Cancer Institute. Risks associated with smoking cigarettes with low machine-measured yields of tar and nicotine. Bethesda, Maryland: US Department of Health and Human Services, National Institutes of Health, National Cancer Institute October, 2001, Report No.02-, 5074.

23 Brown, Williamson Tobacco Corporation LTC, Philip Morris USA, R. J. Reynolds Tobacco Company. The 1999 Massachusetts benchmark study: final report, July 24, 2000

24 Ohlemiller TJ, Villa KM, Braun E, et al. Test methods for quantifying the propensity of cigarettes to ignite soff furnishings. NIST Special Publication 851: US Department of Commerce, Technology Administration, National Institute of Standards and Technology, 1993.

\section{ELECTRONIC PAGES}

\section{Tobacco Control Online: www.tobaccocontrol.com}

I5

he following electronic only articles are published in conjunction with this issue of Tobacco Control.

\section{Tobacco industry successfully prevented tobacco control legislation in Argentina}

E M Sebrié, J Barnoya, E J Pérez-Stable, S A Glantz Objective: To evaluate how transnational tobacco companies, working through their local affiliates, influenced tobacco control policymaking in Argentina between 1966 and 2005.

Methods: Analysis of internal tobacco industry documents, local newspapers and magazines, internet resources, bills from the Argentinean National Congress Library, and interviews with key individuals in Argentina.

Results: Transnational tobacco companies (Philip Morris International, British American Tobacco, Lorillard, and RJ Reynolds International) have been actively influencing public health policymaking in Argentina since the early 1970s. As in other countries, in 1977 the tobacco industry created a weak voluntary self regulating code to avoid strong legislated restrictions on advertising. In addition to direct lobbying by the tobacco companies, these efforts involved use of third party allies, public relations campaigns, and scientific and medical consultants. During the 1980s and 1990s efforts to pass comprehensive tobacco control legislation intensified, but the organised tobacco industry prevented its enactment. There has been no national activity to decrease exposure to secondhand smoke.

Conclusions: The tobacco industry, working through its local subsidiaries, has subverted meaningful tobacco control legislation in Argentina using the same strategies as in the USA and other countries. As a result, tobacco control in Argentina remains governed by a national law that is weak and restricted in its scope.

(Tobacco Control 2005;14:e2) http://www.tobaccocontrol. com/cgi/content/full/14/5/e2

\section{Tobacco industry consumer research on socially acceptable cigarettes P M Ling, S A Glantz}

Objective: To describe tobacco industry consumer research to inform the development of more "socially acceptable" cigarette products since the 1970s.

Methods: Analysis of previously secret tobacco industry documents.

Results: 28 projects to develop more socially acceptable cigarettes were identified from Philip Morris, RJ Reynolds, British American Tobacco, and Lorillard tobacco companies. Consumer research and concept testing consistently demonstrated that many smokers feel strong social pressure not to smoke, and this pressure increased with exposure to smoking restrictions. Tobacco companies attempted to develop more socially acceptable cigarettes with less visible sidestream smoke or less odour. When presented in theory, these product concepts were very attractive to important segments of the smoking population. However, almost every product developed was unacceptable in actual product tests or test markets. Smokers reported the complete elimination of secondhand smoke was necessary to satisfy non-smokers. Smokers have also been generally unwilling to sacrifice their own smoking satisfaction for the benefit of others. Many smokers prefer smoke-free environments to cigarettes that produce less secondhand smoke.

Conclusions: Concerns about secondhand smoke and clean indoor air policies have a powerful effect on the social acceptability of smoking. Historically, the tobacco industry has been unable to counter these effects by developing more socially acceptable cigarettes. These data suggest that educating smokers about the health dangers of secondhand smoke and promoting clean indoor air policies has been difficult for the tobacco industry to counter with new products, and that every effort should be made to pursue these strategies.

(Tobacco Control 2005;14:e3) http://www.tobaccocontrol. com/cgi/content/full/14/5/e3 